\title{
Work as a Realm of Social Freedom
}

Nicholas H. Smith

\section{Introduction: realms of necessity and freedom}

Many progressives about work have been oriented in their thinking by the distinction, famously made by Marx in Volume Three of Capital, between 'the realm of necessity' and 'the true realm of freedom'. ${ }^{1}$ The point of the distinction, at least as interpreted by many of Marx's readers, is to get a clearer picture of the relationship between hopes that attach to work and hopes that attach to other forms of human activity. The distinction does this first by way of a reminder of the fundamental context in which work occurs: the need for human beings to produce the stuff that keeps them alive. Subjection to that need, and to the laws that govern the metabolism between 'man' and 'nature', is the unavoidable, universal condition of human life. Human beings can make their metabolism with nature more effective; they can reach a better understanding of the laws of nature and thereby gain more control over it; and they can organize themselves so as to exercise this control for collective human purposes and the common good. In these three respects, there is room for freedom in the realm of necessity and a basis for hope in the realization of human potential through work. But this potential is limited by 'external' constraints imposed by nature-what Marx also calls 'natural necessity'. The potential for human self-realization is unlimited, however, in that realm of action in which the development of human powers is pursued 'as an end in itself'. The development of human capacities for its own sake, as an end-in-itself, is different, in Marx's view, from their development in the course of pursuing some other 'external' end, such as the maintenance and reproduction of life, the end pursued in the realm of necessity. Only action directed at the former end belongs to the 
'true realm of freedom' as Marx defines it here. We should not think of work, or 'material production proper', as the kind of action that is apt for the true realm of freedom; on the contrary, as Marx concludes the passage by stating, "the reduction of the working day is the basic prerequisite'. By metabolizing with nature (through labour) more effectively, by understanding nature better, and by organizing themselves in relation to it for the common good, human beings can hope to realize this prerequisite more adequately. The true realm of freedom, enacted through non-work, thus has the partial freedom available in the realm of necessity, enacted through work, 'as its basis'. ${ }^{2}$ Though the hopes we attach to work should be distinguished from the hopes we attach to non-work, they are ultimately bound up with each other, and we should have both in view (Marx is urging) when attempting to think progressively about work.

The view Marx actually expresses here can be contrasted with two views that subsequently became known as 'Marxist'. ${ }^{3}$ One is that it is only through labour, understood as participation in the process of material production, that human beings realize their essential nature and attain 'true' freedom. Such labour essentialism, if we may call it that, has been used ideologically to justify some of the most brutal forms of oppression in human history, as if labour under no matter what conditions sufficed to make human beings free; or as if those not directly involved in material production, no matter what else they did, were lacking in the essential human quality. This no doubt helps to explain the low regard in which labour essentialism is usually held nowadays. But even if labour essentialism is considered independently of its ideological abuse, and is taken to assert that it is only labour-under-certain-conditions-for example, democratically organized labour - that constitutes the human essence, it is still the wrong way to think progressively about work, in Marx's view, because it fails to capture the essentially limited character of the freedom available through labour. The other mistaken view-let's call 
it labour libertarianism - is that labour is a contingent, not a natural, necessity, and that human beings will only be able to realize themselves fully once the need for labour has disappeared. On this view, there is no real sense in which freedom of any sort is at stake in the sphere of production qua realm of necessity: so long as human beings have to work, freedom will elude them. Our social hopes should therefore be shaped by an ideal of self-organizing productive processes, processes that can basically look after themselves while the people do as they choose. Only a realm in which human beings are not constrained in how they spend their time, in which they are free above all from the compulsion to labour, constitutes the true realm of freedom in the labour-libertarian view. We then have on our horizon, as an orienting hope, not so much the reduction as the abolition of the working day. But this is not how Marx suggests we should orient ourselves in relation to work, at least not when he invokes the distinction between the realm of necessity and the true realm of freedom. For it is a crucial feature of that distinction that some freedom is available through work, and that the freedom available through non-work supervenes on that lower-level freedom.

Marx's articulation of social hopes around work, as formulated in the distinction between the realm of necessity and the true realm of freedom, is at once more nuanced and more realistic than both labour essentialism and labour libertarianism, the close association of those views with Marxist doctrine notwithstanding. It is more nuanced because it allows for degrees of freedom in both work and non-work. It is more realistic because it conceives those freedoms as interrelated, as grounded in the provision of material necessity without being reduceable to activity responsible for that provision. But while the distinction between the realm of necessity and the true realm of freedom, as formulated by Marx, has these advantages, it might also seem to have less welcome consequences. For example, what are we to make of work whose purpose, on the face of it, has little to do with the satisfaction of material needs? On the face of it, what 
Marx calls 'material production proper', or production aimed at the maintenance and reproduction of life, corresponds only to certain sectors of the division of labour: primary production, obviously, and some elements of manufacture, but in what sense is the work activity of a teacher, hairdresser, taxi-driver, or a whole swathe of service-providers aimed at meeting the necessities of life? In what sense are workers in the research-communications industry, including many of the readers and writers of this book, engaged in a metabolism with nature when they work - any more so than when they do not work? Of course, the modern worker needs the wages or payments exchanged for their labour in order to meet life's necessities - food, energy sources, medicines, et cetera. But only a small minority are directly involved in the production of that stuff, and thus in what Marx calls 'material production proper'. And of those engaged in labour that is non-productive in this sense, many do so for wages in excess of the level required to keep them and their dependants alive. ${ }^{4}$ If we also take into account the availability of benefits to protect against hunger and disease, the sense in which work in general represents a realm of necessity, a realm of natural necessity, in the modern world becomes unclear.

We can look at this from two perspectives. First, there are needs that are satisfied, either directly through some labour or indirectly through payment received for it, that don't seem to be determined by natural necessity. I arrive home from a day's teaching and notice that I need a haircut. I satisfy that need by going to the hairdresser, whose need for a taxi home that night is met with the money earned from cutting my hair. The taxi-driver is doing a late shift to help pay for her daughter's tuition fees, and so on. The needs at stake here, those met by the activities of teaching, hairdressing, and taxi-driving, are all real enough. But they do not on that account draw us into the realm of necessity in Marx's sense: they are not literally matters of life and death. It seems clear that a lot of work has this character and is likely to continue to have it in 
the future. If we are to envisage this as a 'realm', then, it does indeed look like a realm of need, but not obviously one of natural necessity. The second, more abstract perspective concerns the necessity of the function served by work. Part of the appeal of Marx's distinction is its sober acknowledgement of the functional constraints on social life. Whatever else human beings do, they first have to produce the material means of their existence through work of various forms. Provision of the material means of existence is an indispensable social function, and in this sense a realm of necessity. But it is not the only function that a viable society must fulfil; it is not the only condition that must be met before other 'higher level' ends can be pursued. For example, any viable society must be able to integrate its members, it must have adequate socialization mechanisms in place for inducting individuals into a shared form of life. A society that lacks such mechanisms is as defective from a functional point of view as one that is unable to produce enough food. A viable human society must also have its own individuation processes; through socialization, individuals must also be able to acquire a sense of self or egoidentity. To the extent that we are talking about indispensable social functions here, we are also talking about distinct realms of necessity. Any society must somehow, no matter what else it goes on to do, socialize, integrate, and differentiate it members, just as it must feed and clothe them. It must be functional with respect to social integration and differentiation, as well as material reproduction (Habermas, 1987). And in being subject to such functional constraints as these, a human society can be said to comprise various realms of necessity.

The two perspectives converge on the thought that need and necessity, considered as 'realms' that map onto the sphere of work, may have a social as much as a natural meaning. There are needs that must be satisfied on account of the position one finds oneself in society, no less than the relation one has to nature as a living organism. It is the fate of each individual human being to have to fit into a society somehow, to find some place in it, just as it is their lot to maintain 
an effective metabolism with nature. The tasks of fitting in, of establishing and maintaining relationships with others, are no more optional for human beings, and in that sense no less necessary, than those of extracting nourishment and energy from the earth and the sun. But they are social rather than natural necessities, and as such have a different 'logic' to them. We can take social as distinct from natural necessity to attach itself to social roles, and these are 'always already' normatively shaped, that is, shaped by expectations of what is socially acceptable and unacceptable in the fulfilment of the role. In any given society there are social roles to be performed, and each individual member of the society, in becoming a member, comes to some understanding of their normative shape and feel of their normative force. We can say that all human beings are subject to social necessity in this sense: they are constrained in their actions by the norms governing the roles that must be performed in the societies of which they have become members.

What would it take for this realm of necessity, the realm of social necessity constituted by given social roles, to become a 'realm of freedom', a realm of social freedom? Or to put the question slightly differently, how is freedom to be obtained in relation to social roles that must be performed - the realm of social necessity that exists - in any given society? More specifically, what would it take for the social roles performed in the activity of work to become part of a realm of social freedom? Or to pose this question slightly differently, how is freedom to be obtained in relation to social roles that, in contemporary societies at least, must be fulfilled through the performance of labour?

It is now widely thought that Hegel might provide a more suitable philosophical framework for addressing such questions than Marx. Hegel has been credited with the conceptual breakthrough that makes social freedom the organizing idea of social philosophy (Neuhouser, 
2000), and Axel Honneth $(2014,2017)$ has proposed a systematic reorientation of critical theory around the idea of social freedom as first articulated in Hegel's Philosophy of Right (1991 [1820]). Honneth's account is the most systematic attempt to date to analyse and critically evaluate contemporary societies from the perspective of the social freedom they make available. It is the most systematic attempt, in other words, at a critique of society from the perspective of the freedom that is available through the performance of social roles. As we would expect, work features prominently in this account, for it is by working that many people play their part in modern society, fit into it and stand out, while conversely the lack of opportunity to work is a major source of social exclusion - of being left without a role at all. But before turning to Honneth's proposals for answering the questions just posed, we need some clarification of the idea of social freedom.

\section{The idea of social freedom}

I've said that social freedom is freedom in the performance of social roles. But what kind of freedom is this? It is the freedom one has in fulfilling a certain role; in being a parent, friend, worker, consumer, citizen, or member of the public, to mention the key social roles whose history over the past two centuries or so Honneth 'normatively reconstructs' in Freedom's Right (2014). Another way of putting this is to say it is the kind of freedom exercised by participating in certain kinds of social relationship, such as the relationship that exists (or is expected to exist) between family members, friends, colleagues, buyers and sellers, and so on. The idea is that one can be more or less free in the enactment of such relationships, not just in the assumption of them. So, the freedom at stake involves more than, say, having the choice to marry this or that person, to have children or not, or to work for this or that company. It also involves living the relationship out in a certain way, actually doing the things that a spouse or 
a colleague does (or is expected to do), and hence fulfilling specific 'role-obligations' (Hardimon, 1994a). The extent to which a particular role-or to use Honneth's terminology, 'action sphere' - admits of social freedom, or for that matter whether it admits of social freedom at all, will depend on how or whether it meets the following criteria. ${ }^{5}$

First, the role must be apt for subjective 'appropriation'. This means that the occupant of the role must be able to give herself over to it, or, to use Hegel's expression, feel 'at home' in the role. We could rephrase this by saying that the occupant of a role that admits of social freedom is able to 'identify' with it, but we should do so cautiously. Appropriation does not entail that the individual defines herself through the role or that she sufficiently expresses her identity through performing the role. Appropriation must also be distinguished from liking the role. One can appropriate a role while wishing to be doing something or being somewhere else. The curtailment of negative freedoms in the performance of a role does not prevent it from being a site of social freedom. What social freedom does exclude, though, is alienation (Jaeggi, 2017). Indeed, to say that a social role must be apt for subjective appropriation in order to count as a site of social freedom is just another way of saying that a role that admits of social freedom does not alienate the person who performs it.

Second, the role or relationship must make it possible for the occupants or relata to 'complete' each other. The performers of roles or participants in relationships that are sites of social freedom contribute to each other's self-realization and enable forms of self-realization that would have been impossible without the role or relationship. Social freedom is thus an essentially shared good. It is essentially shared in that it is possible, and only possible, in relationships where each party to the relationship enjoys it, and where the parties know themselves to be serving each other's good — to be 'completing' themselves — through their 
participation in the relationship. The concept of mutual recognition serves (in this context) to make this idea of agents who know themselves to be realizing each other's good in the performance of a social role more precise. The claim is that in modern societies, we come to this knowledge and express it in three main ways: through the mutual love we show each other in fulfilling our roles as parents, children, life-partners, and friends; in the mutual respect we show each other in fulfilling our roles as citizens or responsible members of humanity at large; and in the esteem we show to each other for achievements and contributions to communities and forms of life we value. But love, respect, and esteem are not just forms of recognition that happen to attach to certain social roles. They provide norms that ought to be applied to those roles, norms that determine whether a given social role is to count as a site of social freedom or not. If a social role becomes detached from its proper form of recognition—say, if parenting were to be oriented predominantly by a norm of individual right-holding, or citizenship by a norm of optimizing group advantage — the role ceases to function as a source of social freedom. Love, esteem, and respect, understood as norms that sustain mutually completing relationships, can thus also be considered as criteria of social freedom, as providing standards by which to judge whether and the extent to which a role, or a particular institutionalization of it, is a site of social freedom. ${ }^{6}$

Third, the people performing the role must have some say in how the role is to be performed. To count as a site of social freedom, a social role must in some sense, to some degree, be regulated by norms that have been determined by the participants in the roles themselves. More precisely, they must be 'co-determined' by them, which is to say determined by them together qua performers of the role or qua relata in the relationship. In acquitting one's responsibilities as parent, friend, worker, and citizen, one typically does not detach oneself from the parties to the relevant relationships, or at least one will not typically do so in the process of making sound 
decisions or acquitting those responsibilities well. Individual self-determination in those contexts is also a matter of collective self-determination or co-determination. Co-determination is a third criterion of social freedom, and the presence of opportunities for taking part in collective decision-making in the performance of a social role is a key indicator of the availability of social freedom there.

Two other points need to be made about social freedom before we look at how and whether work is to be regarded as a realm of social freedom. First, while social freedom is not constituted by the negative freedom to assume a particular social role or not, social freedom does presuppose the subjective freedom to enter relationships that are constitutive of that kind of freedom. Coerced assumption of social roles is thus incompatible with social freedom. Second, when considered from the point of view of the social freedom a role makes available, the role should not be taken in isolation, but in connection with other roles and indeed other goods not connected to social roles at all. The balance between roles, and their integration in a life, must also be taken into account. So, when assessing a role from the perspective of the social freedom available from its performance, one must not only consider the extent to which it satisfies the three criteria just sketched, but also how it fits with other roles and freedoms.

\section{Honneth on social freedom and work}

Given this understanding of social freedom, what are we to make of the claim that work might represent a sphere of social freedom? What are we to make of the suggestion that the idea of social freedom provides the orientation we need for thinking critically and progressively about work? 
For Honneth, these are just the kind of questions we should be asking about work but only under certain methodological constraints. One is that spheres of action be criticized using concepts that are continuous with those that also feature in the best description of those spheres. In particular, the norms that are invoked for the purpose of prescribing how things ought to be in a given sphere should also be indispensable for describing how things are in that sphere and in how they have become what they are. This is a short-hand way of saying that critique, in Honneth's view, should be 'immanent'. Another constraint concerns how the sphere of work is to be conceived. If there are norms in this sphere that are also indispensable for its description, they must be of a very general kind and not linked to a specific mode of activity. Rather, they must apply to the dominant social relationship in which work activity is performed in the modern period, which Honneth takes to be the market relationship. This methodological consideration leads Honneth to conceive the sphere of work, understood as a possible realm of social freedom, as the labour market. It is as a labour market, Honneth thinks, that the sphere of work might be expected to instantiate norms of social freedom and is apt for investigation in terms of its realization of such norms. That markets do (up to a point) instantiate ethical norms and must do so (or appear to do so) in order to function effectively, is an idea Honneth takes to be made plausible by the 'moral economy' tradition. Bringing these methodological convictions together, the question of whether work might represent a sphere of social freedom becomes answerable in terms of the norms that have actually come to hold sway in the modern labour market. We can answer the question affirmatively if we have reason to think that the modern labour market is what it is on account of the social freedom it realizes or plausibly promises to realize, whereas the absence of such normative expectations in this sphere would countenance a negative answer. 
In Freedom's Right, Honneth's answer to this question seems to oscillate between affirmation and denial. On the one hand, if there really were no ethical basis to the organization of labour under capitalism, and no sense in which social freedom were at stake in the performance of waged labour or the exchange of services in a market economy, there would be no 'normative reconstruction' of this sphere of action to undertake. Honneth does himself entertain this possibility, namely that in the case of the labour market the material for a normative reconstruction is lacking, but he puts it to one side and proceeds to narrate a history of the capitalist labour market in terms of gains and losses in social freedom. A positive answer to the question of whether the labour market is a sphere of social freedom thus seems to be implicit in the very execution of the normative reconstruction of this sphere. Furthermore, it is only by adopting the perspective of normative reconstruction on this sphere, that is, by viewing the exchange of services and waged labour as if they together were a sphere of social freedom, that the very meaning of social freedom comes to light. We come to learn what a gain or loss in social freedom amounts to, what the criteria for social freedom are, by looking at the different phases of the capitalist labour market. Thus the 'alienation' and 'degradation' of labour under capitalism described by many labour historians (in particular, Braverman (1974)) shows us what a loss in social freedom measured by the criterion of 'subjective appropriation' is, while conversely attempts to 'humanize' labour show us how gains might be achieved. The exploitation of labour under capitalism shows us what it means to lose social freedom as measured by the criteria of respect and esteem, while struggles for improved working conditions, better pay (pay commensurate with contribution or service), fairer labour laws, and so on, reveal how social freedom can be advanced. And perhaps most decisively, we come to learn what co-determination means concretely, both in the negative through exclusions from decision-making processes and in the positive through various forms of collective selfmanagement in the work context. For these reasons, it seems that Honneth must be committed 
to the view that work is indeed a realm of social freedom, if we mean by that a site of struggle for social freedom, for freedom in the role of working.

On the other hand, there are times when Honneth seems to concede that work should not be regarded as a realm of such freedom after all. He states explicitly that the current economic system, certainly in Western countries, is 'not a sphere of social freedom' for it 'lacks all the necessary characteristics of such a sphere: it is not anchored in role-obligations to which all could agree, and which interweave with each other in a way that could enable subjects to view each other's freedom as the condition of their own' (Honneth, 2014, p.176). He also concedes that the capitalist market, and by implication the modern labour market, is not even expected to deliver social freedom; that social freedom is not even counterfactually presupposed as a pre-contractual norm. For example, he writes that in the moral self-understanding of modernity, it has always been unclear whether the establishment of the market should expand negative freedom or establish social freedom in the sphere of the economy' (Honneth, 2014, p.177). In a similar vein, at the end of his normative reconstruction of the labour market, he notes the predominance in recent times of 'an interpretation of the capitalist market ... according to which the market constitutes a sphere of individual rather than social freedom' (Honneth, 2014, p.249), which is to say a sphere for the expression of subjective freedom, the pursuit of self-interest and mere economic gain. Honneth appears to be saying that this is not just the interpretation that neo-classical economists and capitalists now give to it, as they have always done, but that it has become the dominant interpretation of those whose role it is to work, to participate in the labour market as producers or exchangers of services. Honneth (2014, p.250) invokes this 'shift in the public perception of the market' to explain a general lack of resistance to developments in the labour market associated with neo-liberalism, developments that in nearly all cases involve losses in social freedom. Honneth refers to these 
as 'misdevelopments', but that designation only applies so far as the labour market is expected to realize social freedom in the first place. We could just as well describe them as 'developments' of a sphere of action whose normative basis lies in the promotion of individual freedom and self-interest rather than social freedom.

We could make sense of these apparently contradictory responses to the question of whether work, which under Honneth's methodological strictures means the labour market, represents a realm of social freedom or not by saying that, for Honneth, it once did, in the period stretching from the origins of moral economy to the neoliberal transformation of capitalism, but no longer does. But that leaves us in a troubling position regarding our critical orientation towards the sphere of work. For if we are also bound by Honneth's constraint on the immanence of critique, it would seem that we no longer have recourse to the norms of social freedom when assessing this sphere. We would no longer have recourse to them because they would be 'external' to the object under investigation. The worry can also be put this way: if, as a consequence of accepting Honneth's methodological constraints, we no longer see work as even apt for social freedom, we deprive ourselves of conceptual resources that enable us to see both what is going wrong in this sphere and what we can legitimately hope from it in the future.

We can avoid this problem if we loosen the hold of Honneth's methodological constraints and interpret work as a realm of social freedom somewhat differently. Above all, the assumption that social freedom in the sphere of work is a matter of the norms implicit in market interaction should be dropped. It is problematic not, as has sometimes been argued (Jütten, 2015), because markets are norm-free, but because the market is not the relevant institution for understanding the normativity of work. Modern workplaces may typically be sites of waged labour, but that doesn't mean that they are bound by norms that attach to the marketization of labour, to labour 
insofar as it is exchanged. There are also norms that attach to the work activity itself, to the cooperation and coordination of tasks involved, to the product made or service rendered, and so on. The workplace itself provides the relevant institutional context for the performance of the work role and the availability of social freedom within that role. This is also why, in the moral economy tradition, it is firms rather than markets that provide the material for normative reconstruction (Keat, 2000). Firms can be more or less expansive in the opportunities they provide for social freedom, and workers can enjoy social freedom to a greater or lesser degree in their particular place of work. Honneth would have been truer to the moral economy tradition, not to mention his Frankfurt School heritage, if instead of the labour market he had chosen the site of production itself as the action sphere apt for social freedom.

\section{Towards a social emancipation of work}

The fundamental issue at stake for conceiving work as a realm of social freedom is whether, and how, freedom is to be obtained in the role of producer or provider of services. In distinguishing between the realm of necessity and the true realm of freedom, Marx allowed for some freedom, albeit of a limited sort, in this role. But by tying the role of producer to natural necessity, the distinction loses traction with the modern realities of work. Honneth's normative reconstruction of the ethical basis of the modern labour market promises to put this right. But by the end of this reconstruction we are left with a picture of the labour market as shorn of an ethical basis altogether, as no longer intelligible as a realm of social freedom. If we follow Honneth's methodological strictures around immanent or internal critique, this seems to leave us in the uncomfortable position of lacking criteria, such as the idea of social freedom provides, for criticizing how the role of being a producer or provider of services is actually lived out in modern societies. We seem to be left with the somewhat defeatist conclusion, in other words, 
that the role of producer or provider of services is no longer even apt for social freedom. But this position is a step back from the one with which we began, namely Marx's distinction between the realm of necessity and the true realm of freedom. More specifically, it represents a reversion to what I called labour libertarianism, the view that the role of production offers no hope as far as human freedom is concerned and is best left to self-organizing processes. ${ }^{7}$

In the space remaining, I want briefly to consider the kind of transformations that might be needed to turn work into a realm of social freedom, or reforms that would represent gains in social freedom for people in their role as producers or providers of services. I do not have any new strategies or policies to suggest. The point is rather to take a peek at how some widely discussed proposals for transforming or reforming work might measure up to the criteria of social freedom sketched above.

The institution of a Universal Basic Income (UBI) is thought by some to provide the key to the emancipation of work. Indeed, it is regarded by its most sophisticated philosophical proponent, Philippe van Parijs, as of the same order of emancipatory magnitude as the abolition of slavery and universal suffrage (van Parijs, 1992, p.7). Van Parijs's justification for UBI turns on the claim that it will bring 'real freedom for all', in the sense that it will give everyone the basic means to live as they wish ('real' freedom) without having to work (freedom 'for all' —not just those who work, who like working, or who are looking for work) (van Parijs, 1995). As such, UBI emancipates by way of increasing the individual's negative or subjective freedom. It liberates by removing obstacles to self-realization imposed by the need to work. Clearly, this is a far call from finding freedom in one's role as a producer or provider of services. But UBI might have that effect, too. By providing individuals with more bargaining power in the labour market, UBI might enable them to find occupations they are able to subjectively appropriate, 
thereby going some way in satisfying the first criterion of social freedom. Moreover, if it enables them to leave jobs that fail to show them adequate respect and esteem, or deters them from accepting such jobs, UBI might force employers to be more ethical and so contribute indirectly to a gain in social freedom measured by its second criterion. The potential of UBI to yield gains in social freedom as specified by the third criterion of collective self-management or co-determination in the work activity is less obvious. Indeed, there is a danger that UBI will weaken work collectives, and therefore social freedom, by the very means by which it strengthens negative freedom: cash payments that individuate bargaining power and facilitate exit from a particular set of role-obligations (Gourevitch, 2016). Co-determination at work requires a commitment to the shared goods at stake in the workplace that UBI might undermine.

If, by the social emancipation of work, we mean gains in the social freedom available through work, UBI is unlikely to be the unambiguous instrument of emancipation its advocates typically depict it to be. But we also saw that in order to count as a realm of social freedom at all, a role must not be assumed under coercion. We saw that social freedom presupposes negative freedom even if it is not constituted by it. And UBI looks like a good candidate for ensuring this condition is met with respect to the role of producer or provider of services. Furthermore, UBI might be one way of enabling an integration of roles, of achieving a better balance between the roles of parenthood, friendship, work, leisure, political activity, and so forth, and thus of leading a fulfilling, rounded life. In public, as distinct from philosophical, discourse on UBI, the case is often made that UBI would improve 'work-life' balance. The foregoing thought suggests that there may be something to this from the perspective of social freedom as well. ${ }^{8}$ 
Many progressives about work have their eyes set on recent advances in artificial intelligence and have their hopes for the emancipation of work invested in automation technology. The hope of hopes is that robots will do all the unpleasant work, liberating humans from all the arduous labour that seemed until recently to be the eternal curse of their condition. If that were ever to eventuate, as Hannah Arendt once observed, we would certainly face very different circumstances of freedom than we currently do (Arendt, 1958). That in itself should make us hesitant to orient ourselves this way in our thinking about work. Nonetheless, we can ask if steps in this direction, that is to say the increasing automation of work tasks, represent gains in social freedom. If the effect of automation were simply to make life easier, both in work and outside of it, there would be no gain in social freedom as such. Likewise, if the effect were just to free up time, say by shortening the working week, without making opportunities available for engagement in activity that can be subjectively appropriated or that is mutually completing, it would also be neither progressive nor regressive from a social-freedom point of view. Automation of certain tasks might be emancipatory in the relevant sense if it yielded other tasks whose performance engaged and developed technical or practical capacities. On the other hand, technology that short-circuited opportunities for collective self-management in work, or that displaced deliberative mechanisms by automating decision-making processes concerning common goods, would be bad for social freedom, even if it made aspects of life at work easier or less unpleasant.

Workplace democracy is widely advocated by progressives about work and calls for more of it feature increasingly prominently in public discussions. Not only is the principle that the people who perform a task should have some say over how it is performed, the speed it is performed at, the conditions under which it is performed, and so on, almost universally accepted as a norm, but it is also widely accepted that the withering of workplace democracy 
in recent decades has undermined the integrity of the work role itself. It has been suggested that workplaces have become realms of 'private government' that only a re-empowerment of workers through a return of 'republican freedoms', including freedoms of exit, the rule of law, constitutional rights, and 'voice', can correct (Anderson, 2017, pp.65-6). To the extent that such measures further workplace democracy, they are unambiguously positive from a social freedom point of view. More workplace democracy is a sure way, perhaps the only one, to achieve gains in social freedom.

But it is worth noting that social freedom is a more demanding form of freedom than republican advocates of workplace democracy are typically prepared to countenance. Social freedom is not merely freedom from domination; it is not freedom from being told what to do or the freedom to say no to a boss. It is a richer, more demanding, and more controversial standard of freedom than both the libertarian ideal of negative freedom (van Parijs, 1995) and the republican ideal of freedom from domination (Petitt, 1997). It is a freedom that requires a capacity for subjective appropriation, mutual completion, and self-determination across social roles. Social emancipation, understood as the unleashing of social freedom, is a matter of human beings coming to realize themselves through their key social relationships, relationships we enter in the course of meeting our individual and collective needs. For that reason, it might be more prudent to aim at a legal or political emancipation of work-along the lines suggested by labour libertarianism or republicanism - than a social emancipation. But if we are oriented in our thinking about the emancipation of work by the idea of social freedom, socialism provides the guiding star. ${ }^{9}$

${ }^{1}$ Marx (1991 [1894], pp.958-9). All the phrases in quotation marks in the remainder of this paragraph are from this passage by Marx. 
${ }^{2}$ Exactly what 'partial' means here is a matter of scholarly dispute. Is it partial in the sense of an incomplete realization of the same kind of freedom that is available more fully in the 'true' realm of freedom? Or is it partial in being a particular kind of freedom, distinct from the latter type? For a systematic recent discussion of this issue, see James (2017).

${ }^{3}$ The views I go on to outline serve as 'ideal types' rather than representations of the explicitly held views of particular theorists. I am less interested in classifying theorists into particular camps than in identifying historically effective theoretical possibilities.

${ }^{4}$ By 'non-productive in this sense', I do not mean 'unproductive' in the sense Marx contrasts with 'productive' labour (Marx, 1976 [1867]). Likewise, by 'material production proper', Marx does mean 'really productive' as opposed to apparently productive but 'really unproductive' labour. The distinction between the realm of necessity and the true realm of freedom holds independently of the distinction between productive and unproductive labour and serves different purposes. For Marx, the service work of a teacher or a writer may or may not be productive depending on its role in the generation of capital. It is only productive in the strict sense insofar as it generates capital. The utility of the work, or the quality of the actual service provided, or the naturalness of the need met, are irrelevant for determining whether it is 'productive' or not. The main reason this distinction matters to Marx is that it helps to keep in view the essential antagonism between labour and capital in the performance of the kind of activity that capitalist society rests upon: value-creating work. Marx's distinction between productive and unproductive labour only has application in that context, and so would lack application in a truly free society (the distinction between the true realm of freedom and the realm of necessity, on the other hand, continues to apply).

${ }^{5}$ The content of the idea of social freedom is partly a matter of stipulation. The brief analysis that follows draws largely on the accounts of social freedom more or less explicitly developed 
in Hardimon (1994b), Hegel (1991 [1820]), Honneth (2014), Jaeggi (2017), and Neuhouser $(2000)$

${ }^{6}$ Two misunderstandings should be avoided here. First, a role is never governed by just one norm. It is not as if friends and family members, for example, can drop their obligations to respect each other just because of the special love-obligations they have qua friends and family members. Second, norms of recognition are not attached arbitrarily to roles, but neither are they confined to them. There is some matching between role or 'action-sphere' and norm of recognition, but it is not a simple one-to-one correspondence. See on this Honneth (2003, especially pp.144-7), where Honneth distances himself from Hegel's view on these matters.

${ }^{7}$ The regret Honneth expresses about the influence of the 'spirit of industrialization' and the centrality of the producer role in the socialist tradition reinforces this impression (Honneth, 2017, pp.27-50), even though elsewhere, in Freedom's Right and other works (Honneth, 2012), Honneth does draw — explicitly and with great effect — on the criteria of social freedom and mutual recognition to criticize modern forms of productive action.

${ }^{8}$ For further analysis of UBI from the perspective of the social freedom at stake, see Smith (2019).

${ }^{9}$ Thanks to Keith Breen and Jean-Philippe Deranty for feedback on an earlier draft of this chapter, and to Matt Sims for helping me to clarify a key point in the argument. Of course, responsibility for the remaining obscurities and weaknesses lies squarely with me.

\section{References}

Anderson, E. (2017) Private Government: How Employers Rule Our Lives (and Why We Don't Talk about It), Stephen Macedo (ed.), (Princeton: Princeton University Press). Arendt, H. (1958) The Human Condition (Chicago: University of Chicago Press). 
Braverman, H. (1974). Labor and Monopoly Capital: The Degradation of Work in the Twentieth Century (New York: Monthly Review Press).

Gourevitch, A. (2016) 'The Limits of Basic Income: Means and Ends of Workplace Democracy', Basic Income Studies, 11(1), 17-28.

Habermas, J. (1987) The Theory of Communicative Action, Volume 2, translated by T. McCarthy (Boston: Beacon Press).

Hardimon, M.O. (1994a) 'Role Obligations', Journal of Philosophy, 91(7), 333-63.

Hardimon M.O. (1994b) Hegel's Social Philosophy (Cambridge: Cambridge University Press). Hegel, G.W.F. (1991 [1820]) Elements of the Philosophy of Right, translated by H.B. Nisbet (Cambridge: Cambridge University Press).

Honneth, A. (2003) 'Redistribution as Recognition: A Response to Nancy Fraser', in N. Fraser and A. Honneth, Redistribution or Recognition? (London: Verso), pp.110-97.

Honneth, A. (2012) 'Labour and Recognition: A Redefinition', in A. Honneth, The I in We (Cambridge: Polity Press) pp.56-74.

Honneth, A. (2014) Freedom's Right, translated by J. Ganahl (New York: Columbia University Press).

Honneth, A. (2017) The Idea of Socialism, translated by J. Ganahl (Cambridge: Polity).

Jaeggi, R. (2014) Alienation, translated by F. Neuhouser and A.E. Smith (New York: Columbia University Press).

James, D. (2017) 'The Compatibility of Freedom and Necessity in Marx's Idea of Communist Society', European Journal of Philosophy, 25(2), 270-93.

Jütten, T. (2015) 'Is the Market a Sphere of Social Freedom?', Critical Horizons, 16(2), 187203.

Keat, R. (2000) Cultural Goods and the Limits of the Market (Basingstoke: Macmillan Press). Marx, K. (1976 [1867]) Capital, Volume 1, translated by B. Fowkes (London: Penguin). 
Marx, K. (1991 [1894]) Capital, Volume 3, translated by D. Fernbach (London: Penguin).

Neuhouser, F. (2000) Foundations of Hegel's Social Theory: Actualizing Freedom (Cambridge, MA: Harvard University Press).

Pettit, P. (1997) Republicanism: A Theory of Freedom and Government (Oxford: Clarendon Press).

Smith, N.H. (2019) 'Basic Income, Social Freedom and the Fabric of Justice', Critical Review of International Social and Political Philosophy, 1-21, https://doi.org/10.1080/13698230.2019.1585152 [accessed 20 May 2020].

Van Parijs, P. (1992) 'Competing Justifications of Basic Income', in P. van Parijs (ed.), Arguing for Basic Income (London: Verso), pp.3-46.

Van Parijs, P. (1995) Real Freedom for All: What (if Anything) Can Justify Capitalism? (Oxford: Clarendon). 